\title{
Simple and inexpensive DNA extraction protocol for studying the bacterial composition of sludges used in microbial fuel cells
}

B. Canto-Canché1, M. Tzec-Simá ${ }^{1}$, J.I. Vázquez-Loría ${ }^{1}$,

H. Espadas-Álvarez', B.H. Chí-Manzanero' ${ }^{1}$, R. Rojas-Herrera ${ }^{2}$,

R. Valdez-Ojeda ${ }^{3}$ and L. Alzate-Gaviria ${ }^{3}$

${ }^{1}$ Unidad de Biotecnología, Centro de Investigación Científica de Yucatán, Mérida, Yucatán, México

${ }^{2}$ Universidad Autónoma de Yucatán, Facultad de Ingeniería Química, Mérida, Yucatán, México

${ }^{3}$ Unidad de Energía Renovable, Centro de Investigación Científica de Yucatán, Mérida, Yucatán, México

Corresponding author: B. Canto-Canché

E-mail: cantocanche@cicy.mx

Genet. Mol. Res. 12 (1): 282-292 (2013)

Received April 12, 2012

Accepted November 31, 2012

Published February 4, 2013

DOI http://dx.doi.org/10.4238/2013.February.4.2

ABSTRACT. Bacteria oxidize organic matter and nutrients to produce electric energy in microbial fuel cells (MFC) - a technology of increasing importance because of its sustainability. To improve the performance of MFCs, it is necessary not only to gain a better understanding of MFC engineering designs, but also to improve the understanding of the composition of the microbial communities in MFCs. Fast and efficient DNA extraction protocols that are suitable for extracting diverse bacterial genomes are necessary to identify the bacterial diversity present in MFCs and to further monitor the dynamic changes of microbial communities. This study focused on testing different direct cell lysis protocols to extract DNA from a microbial sludge harvested 
from an MFC. The protocol that achieved the best results was based on a previous study, but was modified by eliminating a chaotropic salt and the special columns used for nucleic acid purification. The efficiency of this less expensive and more straightforward protocol was confirmed by PCR amplification of the 16S rRNA gene and denaturing gradient gel electrophoresis analysis, which confirmed the extraction of multiple genomes. The sequences of 10 clones revealed the presence of phyla, Proteobacteria, Firmicutes and Actinobacteria, comprising both Gramnegative and Gram-positive bacteria. Some of these bacteria were identified at the genus level, e.g., Clostridium, Pseudoxanthomonas, Tistrella, and Enterobacter; these genera have been described in active sludges from wastewater treatment, supporting the congruency of our results. Therefore, this protocol is a useful tool for analysis of the bacteria responsible for energy production in MFCs.

Key words: DNA extraction; Bacterial consortium; 16S rRNA; Microbial fuel cell; Inexpensive DNA protocol; Electrical energy

\section{INTRODUCTION}

A microbial fuel cell (MFC) is a bio-system in which microorganisms consume organic substrates such as sugars and metabolize them to produce energy, i.e., transforming chemical energy to electrical energy (Scott and Murano, 2007; Rezaei et al., 2009; Mohan et al., 2009; Venkata et al., 2010). A typical MFC device is composed of 2 compartments, the anode and cathode, which are separated by a proton exchange membrane. In the anode compartment, organic material is oxidized by microorganisms, thus generating electrons and protons. The electrons are transferred to the cathode compartment through an external electric circuit; meanwhile, the protons are transferred to the cathode compartment through the membrane. MFCs provide dual benefits of wastewater treatment and the production of inexpensive and environmentally friendly energy; this technology has been increasing in importance worldwide over the last decade because of its sustainability (Logan et al., 2006; Kumlanghan et al., 2007; Mohan et al., 2009; Rezaei et al., 2009; Ryu et al., 2011).

Bacteria are living organisms responsible for organic matter and nutrient oxidation that occur in MFCs. Increased understanding of microbial communities in MFC is necessary to design and control the system effectively. To this end, molecular techniques have gained preference for culture-independent bacterial identification (Rojas-Herrera et al., 2008; Ryu et al., 2011). However, the capability of determining microbial diversity largely depends on the quality of the DNA in question.

There is a plethora of protocols for DNA extraction of microbial communities (Zhou et al., 1996; Krsek and Wellington, 1999; Griffiths et al., 2000; Wechter et al., 2003; Chaudhuri et al., 2006; Rojas-Herrera et al., 2008; Ning et al., 2009), including homemade protocols and commercial kits. The latter often allow rapid recovery of nucleic acids, although some kits fail in obtaining nucleic acids in some samples (Hoshino and Matsumoto, 2005; Luna et al., 2006; Hou et al., 2010).

In general, the protocols used to obtain microbial DNA can be classified into 2 strate- 
gies: indirect and direct. Among the indirect procedures, the isolation of microbial cells occurs prior to cell lysis for DNA purification. However, the cell separation procedure causes increased bias in the identification of microorganisms and requires more time and effort; for this reason, other strategies such as the direct lysis protocol are becoming more widely used (Schneegurt et al., 2003; Chaudhuri et al., 2006; Luna et al., 2006; Hou et al., 2010). In direct lysis protocols, the cells are disrupted within the sample matrix and the released nucleic acids are subsequently purified. Many direct extraction methods combine chemical and enzymatic treatments and physical procedures, although some of these protocols are tedious and laborious, with numerous steps. In addition, the required enzymes are expensive and inefficient for most Gram-positive bacteria (Bollet et al., 1991; Maciel et al., 2009).

Any protocol is universally applicable, since the samples are extremely heterogeneous and contain diverse substances. Evaluation and modification of available protocols are often required for microbial analysis in the biological samples under study, which include soil, water, sediment, sludge, feces, and other types of samples (Maciel et al., 2009; Ning et al., 2009; Ariefdjohan et al., 2010). The procedure must extract DNA from a large number of different bacteria, and the recovered nucleic acid must be suitable for subsequent molecular techniques, such as endonuclease restriction or Taq polymerase amplification.

In this report, several protocols for obtaining metagenomic DNA were scaled down to adapt them to be more appropriate for use in MFC samples. Modification of the protocol described by Hurt et al. (2001) resulted in a simpler, faster and less expensive direct lysis protocol than the original, and the DNA was suitable for PCR amplification of the 16S rRNA gene. PCR fragments were also used to confirm whether the isolated bacterial DNA was heterogeneous through denaturing gradient gel electrophoresis (DGGE) analysis. The complexity of the DGGE fingerprinting results demonstrated that the DNA contained several genomes. Cloning and sequencing of 10 rDNA clones showed that Gram-negative and Gram-positive bacteria were disrupted. This result validated our protocol since Gram-positive bacteria are recalcitrant for DNA extraction, which indicated that this method is suitable for inexpensive analysis of the microbial community composition in sludges derived from MFCs.

\section{MATERIAL AND METHODS}

\section{Biological material}

The microbial inoculum mixture was prepared by $30 \mathrm{~g} / \mathrm{L}$ combining soil, $300 \mathrm{~g} / \mathrm{L}$ cow manure, $150 \mathrm{~g} / \mathrm{L}$ pork manure, $1.5 \mathrm{~g} / \mathrm{L} \mathrm{Na}_{2} \mathrm{CO}_{3}, 5 \mathrm{~g} / \mathrm{L}$ commercial sucrose, and tap water, with a 1-L final volume. The acclimation of inoculum was performed according to procedure described by Alzate-Gaviria et al. (2008). A glass H-type MFC was used, which had equal volumes of anode and cathode compartments $(300 \mathrm{~mL})$; the chambers were separated by a proton exchange membrane (Nafion 117, DuPont, Wilmington, DE, USA), as described by Alzate-Gaviria et al. (2010). The MFC was inoculated and fed with artificial wastewater containing glucose; it was operated in fed-batch mode (hydraulic retention time of $24 \mathrm{~h}$ ) according to the description provided by Alzate-Gaviria et al. (2008). The power density was $5 \mathrm{~W} /$ $\mathrm{m}^{2}$ when the residual semisolid material (sludge) was harvested from the anode chamber (40 $\mathrm{mL}$ ), centrifuged, resuspended in $20 \mathrm{~mL}$ fresh artificial wastewater, aliquoted (1-mL volume) and stored at $-80^{\circ} \mathrm{C}$ until use. 


\section{DNA extraction}

The protocols were scaled down to use $0.3 \mathrm{~g}$ starting sample, and the reagents were used proportionally, according to each protocol. Table 1 shows the list of protocols tested in this study and the minor modifications of each. Modifications in protocol 6 were as follows. Bacterial genomic DNA was obtained by freeze fracture. The sample was centrifuged at $15,000 \mathrm{~g}$ for $5 \mathrm{~min}$, then the cell pellet was ground in liquid nitrogen, and $750 \mu \mathrm{L}$ DNA extraction buffer was added, and the sample was rapidly thawed in a $65^{\circ} \mathrm{C}$ water bath $(10$ $\mathrm{min}$ ). The freeze-thaw procedure was repeated four times and centrifuged as above for $10 \mathrm{~min}$. The DNA in the resulting lysate was purified by extraction with $600 \mu \mathrm{L}(24: 1)$ chloroformisoamyl alcohol. The aqueous phase was precipitated with 0.6 volume of isopropyl alcohol and centrifuged at $15,000 \mathrm{~g}$ for $10 \mathrm{~min}$. The pellet was washed with $70 \%$ ethanol, air dried and resuspended in $30 \mu \mathrm{L}$ ultrapure DNase/RNase-free distilled water (Invitrogen, Carlsbad, CA, USA). The RNA was removed by a 60-min incubation with RNaseA (Sigma, St. Louis, MO, USA) at $37^{\circ} \mathrm{C}$, and the final sample concentration was $10 \mu \mathrm{g} / \mathrm{mL}$. DNA integrity was assessed by ethidium bromide-stained agarose gel electrophoresis.

\section{PCR amplification}

16S rRNA sequence amplifications were performed in $25-\mu \mathrm{L}$ volumes containing 1.5 $\mathrm{mM} \mathrm{MgCl}, 0.2 \mathrm{mM}$ dNTPs, $1 \mu \mathrm{M}$ of each primer (forward: 5'-AGAGTTTGATCCTGGCTCA G-3'; reverse: 5'-CCGTCAATTCCTTTGAGTTT-3'; Luna et al., 2006), 1.4 U Taq polymerase (Invitrogen) and $2 \mu \mathrm{L}$ total chromosomal DNA. The oligonucleotide sequences target the V1 and V5 hypervariable regions on $16 \mathrm{~S}$ rRNA genes and amplify approximately $880 \mathrm{bp}$. The negative control contained the PCR mixture without DNA template. PCR consisted of initial denaturation at $94^{\circ} \mathrm{C}$ for $5 \mathrm{~min}$, followed by 35 cycles of $94^{\circ} \mathrm{C}$ for $30 \mathrm{~s}, 42^{\circ} \mathrm{C}$ for $60 \mathrm{~s}$ and $72^{\circ} \mathrm{C}$ for $60 \mathrm{~s}$, and a final extension at $72^{\circ} \mathrm{C}$ for $10 \mathrm{~min}$. After PCR, $5-\mu \mathrm{L}$ aliquots were run on a $1 \%$ agarose-TAE gel (40 mM Tris-HCl, $20 \mathrm{mM}$ acetic acid, $1 \mathrm{mM}$ EDTA, $\mathrm{pH}$ 8.0), containing ethidium bromide for DNA staining and visualization. A DNA marker (1 kb, Invitrogen) was included as a standard for the calculation of the DNA fragment sizes. The gel was run in 1X TAE buffer and photographed using a gel documentation system (Gel Doc EQ, Biorad, Hercules, CA, USA).

\section{Analysis of 16S rRNA genes by DGGE}

The first reaction was conducted as above, followed by a touchdown annealing reaction to reamplify the V3-V5 region ( $\sim 580 \mathrm{bp})$. Primers for the second reaction included a clampcontaining forward primer: 5'-CGCCCGCCGCGCGCGGCGGGCGGGGCGGGGGCACGG GGGGCCTACGGGAGGCAGCAG-3' (Muyzer et al., 1993) and the reverse primer described above.

The amplicons were separated on a $6 \%$ polyacrylamide gel with a denaturing gradient between 30 and $70 \%$ (100\% denaturant contained $8 \mathrm{M}$ urea and $40 \%$ formamide).

Samples were electrophoresed for $18 \mathrm{~h}$ at $60^{\circ} \mathrm{C}$, and $60 \mathrm{~V}$ in $1 \mathrm{X}$ TAE buffer. The gels were stained for $45 \mathrm{~min}$ in $1 \mathrm{X}$ TAE buffer with $1 \%(\mathrm{w} / \mathrm{v})$ SYBR Green nucleic acid stain (Molecular Probes, Eugene, OR, USA) and photographed using a gel documentation system (Gel Doc EQ, Biorad). 


\section{Cloning procedures, sequencing and microbial identification}

The PCR amplicon obtained with the template from protocol 6 was purified with a QIAquick PCR Purification Kit (Qiagen, Valencia, CA, USA) and ligated into the cloning vector, pCRII-TOPO, using the TOPO-TA cloning kit (Invitrogen). White colonies were screened by colony-PCR using the same pair of primers. The clones containing the expected insert were inoculated into $3 \mathrm{~mL}$ LB liquid medium supplemented with $50 \mu \mathrm{g} / \mathrm{mL}$ kanamycin and incubated overnight. DNA plasmids were then extracted by alkaline lysis according to the procedure described by Zhou et al. (1996) and subjected to EcoRI digestion. For sequencing, the plasmid DNAs were extracted using the QIAprep Spin Miniprep Kit (Qiagen). The most similar sequences were retrieved by using the Basic Local Alignment Search Tool (BLAST, http://www.ncbi.nlm.nih. gov/; Altschul et al., 1990). For assignment of the clone, the naive Bayesian-based classifier tool from the Ribosomal Database Project (RDP, http://www.life.uiuc.edu/; Wang et al., 2007) was used.

\section{RESULTS}

Obtention of high-yield and PCR-suitable DNA is crucial for bacterial community molecular analysis. Six unmodified or slightly modified DNA extraction protocols were tested in this study (Table 1).

In protocol 1 (Griffiths et al., 2000), the grinding step was modified by using glass beads and resulted in obtaining negligible amounts of DNA. Extraction with the unmodified procedure described by Chaudhuri et al. (2006) also produced a negative result. In addition, we attempted DNA extraction by using the QIAamp DNA Stool Mini Kit (Qiagen), which is recommended for soil and similar recalcitrant samples, but no DNA was recovered. Table 2 shows a summary of these results.

\begin{tabular}{|c|c|c|c|}
\hline Protocols & Reference & Description & Modification \\
\hline 1 & Griffiths et al. (2000) & $\begin{array}{l}\text { A rapid CTAB-based method for co-extraction } \\
\text { of microbial DNA and RNA from } \\
\text { natural environments }\end{array}$ & $\begin{array}{l}\text { Slightly modified. Use of glass beads } \\
\text { during maceration in pre-chilled mortar } \\
\text { (in the presence of CTAB) instead of } \\
\text { FP120 bead beating system. The rest } \\
\text { of the method unmodified }\end{array}$ \\
\hline 2 & QIAamp DNA Stool Mini kit & Commercial kit & Unmodified \\
\hline 3 & Chaudhuri et al. (2006) & $\begin{array}{l}\text { Lysis with Tris-HCl-EDTA buffer supplemented } \\
\text { with proteinase K and sonication }\end{array}$ & Unmodified \\
\hline 4 & Rojas-Herrera et al. (2008) & $\begin{array}{l}\text { Pretreatment with lysozyme-containing } \\
\text { buffer followed by freeze and thaw cycles. } \\
\text { Lysis by SDS and isolation of DNA with } \\
\text { silica gel (glass milk) }\end{array}$ & Unmodified \\
\hline 5 & Hurt et al. (2001) & $\begin{array}{l}\text { Ground of frozen (liquid nitrogen) samples in } \\
\text { guanidine isothiocyanate-containing } \\
\text { denaturing buffer. DNA extraction with } \\
\text { CTAB-SDS-containing buffer. } \\
\text { Use of QIAGEN resin column and } \\
\text { Wizard column to purify nucleic acids. }\end{array}$ & $\begin{array}{l}\text { Slightly modified: no use of Qiagen resin } \\
\text { and Wizard columns }\end{array}$ \\
\hline 6 & This study & Based on method 5, with technical modifications & $\begin{array}{l}\text { Freeze-thaw lysis method. No use of } \\
\text { guanidine isothiocyanate buffer, } \\
\text { hydrolytic enzymes and purification } \\
\text { columns. Details in Material and } \\
\text { Methods section. }\end{array}$ \\
\hline
\end{tabular}

All methods were scaled down to $0.3 \mathrm{~g}$ sample, using reagents proportionally. Unmodified means no technical changes, only the scaling down of the sample and reagents. $\mathrm{CTAB}=$ cetyltrimethylammonium bromide; EDTA= ethylenediaminetetraacetic acid; SDS = sodium dodecyl sulfate. 
Table 2. Summary of results from protocols tested in this study.

\begin{tabular}{llcll}
\hline Protocols & Yield $(\mu \mathrm{g}$ DNA/g sludge) & $\mathrm{A}_{260} / \mathrm{A}_{230}$ & $\mathrm{~A}_{260} / \mathrm{A}_{280}$ & PCR (fragment of 16S rRNA gene) \\
\hline 1 & $\begin{array}{c}\text { Not evaluated. Extremely poor } \\
\text { recovery of nucleic acids }\end{array}$ & - & - & Not evaluated \\
2 & No detectable recovery of DNA & - & - & Not evaluated \\
3 & No detectable recovery of DNA & - & - & Not evaluated \\
4 & 3.41 & 1.95 & 1.78 & Amplification \\
5 & 4.89 & 1.90 & 1.89 & Amplification \\
6 & 6.82 & 2.26 & 1.82 & Amplification \\
\hline
\end{tabular}

Three of the 6 assays were successful in extracting DNA from the MFC sludge used herein, including the silica-based protocol reported by Rojas-Herrera et al. (2008), 2 protocols based on Hurt et al. (2001), with minor (protocol 5) and major modifications (protocol 6). In protocol 5, the commercial columns used at the end in the original protocol were not used; the remainder of the procedure was followed as reported by these authors.

In protocol 6, we introduced major changes. We used the aforementioned freeze-thaw method (repeated 4 times to fracture the cells) instead of the chaotropic agent, guanidine isothiocyanate. As described above, purification columns were excluded.

Protocols 4, 5 and 6 resulted in obtaining high molecular weight DNA (Figure 1A). Similar ratios of absorbance at $\mathrm{A}_{260} / \mathrm{A}_{230}$ were observed, which were near 1.8. The ratios at $\mathrm{A}_{260} / \mathrm{A}_{280}$ were also within the acceptable range (Table 2). All of the resultant products were suitable templates for PCR amplification (Figure 1B).
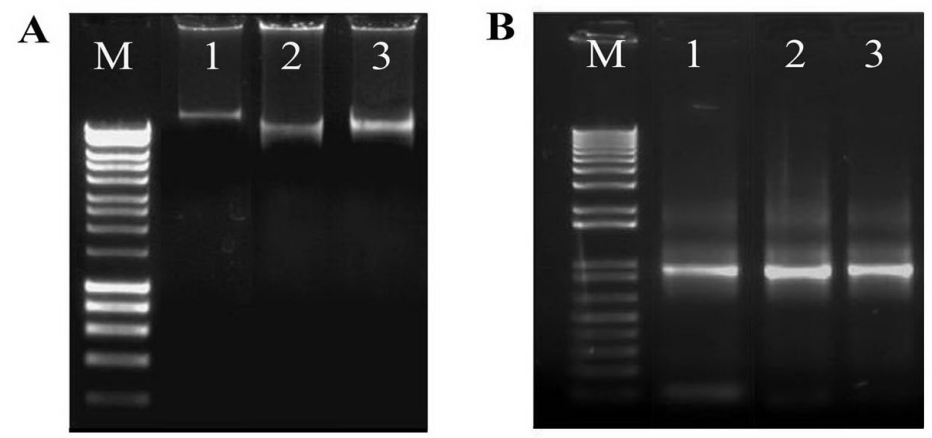

Figure 1. A. Electrophoresis analysis on $1 \%$ agarose gel of microbial fuel cell-sludge bacterial DNA extracted by protocols tested. B. PCR amplification of a fragment of $16 \mathrm{~S}$ rRNA gene. In both figures: lane $1=$ from protocol 4; lane 2 = from protocol 5; lane 3 = from protocol 6; lane $M=1-\mathrm{kb}$ molecular weight marker (Invitrogen).

Short and straightforward methods are preferred for bacterial community analyses (Aidar and Line, 2007; Hamady and Knight, 2009). Protocols 4, 5 and 6 were suitable methods, as they were relatively easy and quick ( 6,5 and $4 \mathrm{~h}$, respectively). To evaluate whether these protocols were capable of extracting different types of bacteria, DGGE analysis was used for rapid comparisons (Figure 2). The V3-V5 DGGE fingerprints showed the presence of many distinguishable and shared bands among these extraction protocols (Figure 2). The observation of multiple DNA bands indicated that these protocols extracted metagenomic DNA. 
The fingerprint from protocol 6 (Figure 2, lane 3) showed the greatest number of bands, which suggests that this protocol is useful for the study of bacterial diversity in MFC sludges.

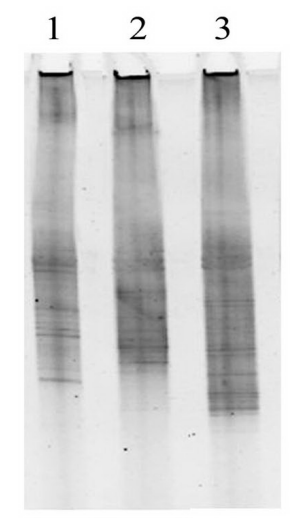

Figure 2. Denaturing gradient gel electrophoresis analyses of $16 \mathrm{~S}$ rRNA genes of bacterial consortium from a microbial fuel cell. Polymerase chain reaction amplifications were conducted on V3-V5 region. Lane 1 = fingerprint from protocol 4; lane 2 = fingerprint from protocol 5; lane 3 = fingerprint from protocol 6 .

Results obtained from DGGE analysis prompted us to choose the DNA template from protocol 6 to identify the bacterial composition of the MFC sludge sample. For this approach, the V1-V5 PCR product was gel-purified, ligated into the TOPO-TA vector and the clones were analyzed by $E c o$ RI digestion (data not shown); 10 of these clones were sequenced. Seven clones showed similarities with Proteobacteria [Tistrella mobilis, Novosphingobium pentaromativorans (Alphaproteobacteria), Acidovorax sp (Betaproteobacteria), Pseudoxanthomonas sp, Enterobacter cloacae (Gammaproteobacteria)], 1 clone with Arcanobacterium sp (Phyllum Actinobacteria) and 2 clones with Clostridia (Phyllum Firmicutes). The bacterial identification results demonstrated that this protocol was able to disrupt Gram-positive bacteria, as 3 of these clones had similarity with this type of bacteria (Table 3 ).

Table 3. Taxonomic classification of 10 clones from the microbial fuel cell, according to their 16S rRNA gene sequences.

\begin{tabular}{|c|c|c|c|c|}
\hline $\begin{array}{l}\text { Closest sequence or } \\
\text { organism in GenBank }\end{array}$ & Similarity $(\%)$ & Phyla & $\begin{array}{l}\text { Lower taxonomic rank } \\
\text { assignment by RDP classifier* }\end{array}$ & Gram \\
\hline Pseudoxanthomonas sp & 95 & Firmicutes & Genus Pseudoxanthomonas [100\%] & Negative \\
\hline Tistrella mobilis & 96 & Proteobacteria & Genus Tistrella $[100 \%]$ & Negative \\
\hline Novosphingobium pentaromativorans & 92 & Proteobacteria & Class Alphaproteobacteria [99\%] & Negative \\
\hline Acidovorax sp & 99 & Proteobacteria & Family Comamonadaceae [100\%] & Negative \\
\hline Tistrella mobilis & 96 & Proteobacteria & Genus Tistrella $[100 \%]$ & Negative \\
\hline Unculture bacterial clone & 97 & Firmicutes & Subfamily Clostridiaceae [100\%] & Positive \\
\hline Unculture ruminal bacterium & 95 & Firmicutes & Genus Clostridium [100\%] & Positive \\
\hline Arcanobacterium phocae & 97 & Actinobacteria & $\begin{array}{l}\text { Family Actinomycetaceae [96\%]; } \\
\text { Genus Arcanobacterium [75\%] }\end{array}$ & Positive \\
\hline Unculture bacterium & 79 & Proteobacteria & Class Alphaproteobacteria $[90 \%]$ & Negative \\
\hline Enterobacter cloacae & 98 & Proteobacteria & Family Enterobacteriaceae $[100 \%]$ & Negative \\
\hline
\end{tabular}

*Classification was carried out using the Ribosomal Database Project (RDP) classifier with a confidence threshold of $95 \%$. The percentage of confidence of correct taxonomic rank, calculated by the classifier assignment in RDP, is shown in brackets. The formal taxonomic ranks in RDP classifier are, from the highest rank to the lowest, domain, phylum, class, order, family, genus, and species. 16S RNA gene fragments sequenced here were around $880 \mathrm{bp}$ and sequences submitted to BLAST and RDP were $>500 \mathrm{bp}$. 


\section{DISCUSSION}

Nucleic acid extraction is one of the most important procedures in molecular microbial research. The most efficient methods for investigating microbial complexity in sedimentary matrix (sludges) are based on direct (in situ) lysis, as this technique introduces less bias in the analysis (Schneegurt et al., 2003; Luna et al., 2006; Maciel et al., 2009). We tested a number of protocols for extracting DNA from an MFC sludge sample. As summarized in Table 1, the evaluated protocols combine some of the most popular physical (e.g., bead mill homogenization, sonication, freeze-thawing, milling, and grinding), enzymatic (e.g., lysozyme or proteinase $\mathrm{K}$ ) and chemical [e.g., use of cetyltrimethylammonium bromide (CTAB) or sodium dodecyl sulfate (SDS) detergents] procedures. However, the MFC sludge sample was recalcitrant for DNA extraction with 3 of the 6 protocols tested. Successful results were obtained with protocols 4, 5 and 6. Protocol 4, described by Rojas-Herrera et al. (2008), uses lysozyme and glass milk, which raises the price of DNA extraction; however, this procedure is also fast and in our hands has been successful for other types of samples, e.g., soil, sediments and marine water; thus, we decided to use it for comparison. This protocol was capable of extracting DNA suitable for PCR amplification (Figure 1, lane 1).

Protocols 5 and 6 were based on the methods of Hurt et al. (2001), although we eliminated the use of guanidine isothiocyanate in the latter protocol, and the sample was repeatedly submitted to (liquid nitrogen)-freeze-thaw and grinding in CTAB-SDS-containing extraction buffer. As shown in Figure 1A, lanes 2 and 3 show a comparison of the results obtained from protocols 5 and 6, and they demonstrate that cellular disruption occurred despite elimination of the chaotropic agent. The original procedure uses Qiagen and Wizard columns to purify the nucleic acids; we obviated these steps and the resultant DNA was a suitable template for amplification of the target fragment of the 16S rRNA gene (Figure 1B, lanes 2 and 3), which demonstrated that we could exclude the final purification steps.

We applied DGGE analysis from templates obtained from protocols 4, 5 and 6 to investigate whether these protocols extracted metagenomic DNA from the MFC, and to determine which extract showed the most diversity. The DGGE profiles presented in Figure 2 indicate that protocol 6 is suitable for the study of bacterial composition in the sludge, as a greater number of bands were amplified with template from this protocol. Many of the bands were shared with the fingerprinting results amplified with templates from protocols 4 and 5. Each of the 3 templates enriched a few bands that were not observed with the others. It is believed that the variability of DGGE bands may be higher for less-abundant genome targets than those more-abundant targets (Gonzalez-Franco et al., 2009; Martínez-Alonso et al., 2010); thus, intense and common DNA bands observed in the 3 DGGE fingerprints likely correspond to predominant bacteria. Extraction and purification of DNA without bias is difficult, and no protocol is completely effective for DNA extraction of the total community (Peng et al., 2007; Vanysacker et al., 2010). Therefore, the use of complementary DNA extraction protocols is recommended. Based on our results, we suggest the use of protocol 6 in combination with protocol 4 to perform microbial analysis of the electrogenic process in MFCs.

The DNA template obtained from protocol 6 was used to analyze the bacterial composition in the sludge sample. This straightforward and rapid protocol was capable of lysing both Gram-negative and Gram-positive cells (Table 3), which are more difficult to disrupt (Schneegurt et al., 2003; Hoshino and Matsumoto, 2005). Gram-positive Clostridiaceae bac- 
teria were identified herein; these bacteria have been reported in active sludges (Scott and Murano, 2007; Goberna et al., 2009; Ryu et al., 2011). In addition to Gram-positive bacteria, the other sequences revealed the presence of Gram-negative bacteria belonging to the genera Novosphingobium, Tistrella, Enterobacter, Pseudoxanthomonas, and Acidovorax. These genera have been described in active sludges from wastewater treatment (Khan, 2002; Sohn et al., 2004; Zhua et al., 2008; Sarma et al., 2010) and polycyclic aromatic hydrocarbon-contaminated soils (Achuthan et al., 2006). E. cloacae has been recently reported as able to produce electricity in an MFC (Rezaei et al., 2009). Therefore, the bacteria identified in the present study are congruent with reports regarding similar samples. Our results support our recommendation for the use of this protocol for studying MFC microbial communities. Moreover, this protocol is attractive since it uses common molecular laboratory reagents, which is important for third world research institutions or laboratories that face difficulties in obtaining reagents.

\section{CONCLUSION}

In summary, the simple DNA extraction direct method adapted herein is suitable for bacterial analysis in MFCs. The protocol is rapid, straightforward and inexpensive, and enables the isolation of a high-molecular weight DNA material containing Gram-positive and Gramnegative bacteria that is suitable for PCR amplification of 16S rRNA genes. The simplicity and speed of this protocol renders it amenable to handling DNA extraction from multiple MFC sludge samples, which is required to adequately study the microbial dynamics inside of MFCs. These studies have become increasingly important, as the information obtained from them will be used to improve MFC efficiency in the production of electrical energy.

\section{ACKNOWLEDGMENTS}

Research supported by Consejo Nacional de Ciencia y Tecnología (CONACyT, México), project \#106416, \#55099 and \#51290. J.I. Vázquez-Loría and H. Espadas-Álvarez were recipients of Centro de Investigación Científica de Yucatán fellowships.

\section{REFERENCES}

Achuthan C, Rejish Kumar VJ, Manju NJ, Philip R, et al. (2006). Development of nitrifying bacterial consortia for immobilizing in nitrifying bioreactors designed for penaeid and non-penaeid larval rearing systems in the tropics. Indian J. Mar. Sci. 35: 240-248.

Aidar M and Peres Line SR (2007). A simple and cost-effective protocol for DNA isolation from buccal epithelial cells. Braz. Dent. J. 18: 148-152.

Altschul SF, Gish W, Miller W, Myers EW, et al. (1990). Basic local alignment search tool. J. Mol. Biol. 215: 403-410.

Alzate-Gaviria L, Fuentes-Albarrán C, Álvarez-Gallegos A and Sebastian PJ (2008). Generación de electricidad a partir de una celda de combustible microbiana tipo PEM. Interciencia 33: 503-509.

Alzate-Gaviria L, González K, Peraza I and García O (2010). Evaluación del desempeño e identificación de exoelectrógenos en dos tipos de celdas de combustible microbianas con diferente configuración en el ánodo. Interciencia 35: 19-25.

Ariefdjohan MW, Savaiano DA and Nakatsu CH (2010). Comparison of DNA extraction kits for PCR-DGGE analysis of human intestinal microbial communities from fecal specimens. Nutr. J. 9: 23.

Bollet C, Gevaudan MJ, de Lamballerie X, Zandotti C, et al. (1991). A simple method for the isolation of chromosomal DNA from Gram positive or acid-fast bacteria. Nucleic Acids Res. 19: 1955.

Chaudhuri SR, Pattanayak AK and Thakur AR (2006). Microbial DNA extraction from samples of varied origin. Curr. Sci. 91: 1697-1700. 
Goberna M, Insam H and Franke-Whittle IH (2009). Effect of biowaste sludge maturation on the diversity of thermophilic bacteria and Archaea in an anaerobic reactor. Appl. Environ. Microbiol. 75: 2566-2572.

Gonzalez-Franco AC, Robles-Hernandez L, Nuñez-Barrios A, Strap JL, et al. (2009). Molecular and cultural analysis of seasonal actinomycetes in soils from Artemisia tridentata habitat. Phyton 78: 83-90.

Griffiths RI, Whiteley AS, O’Donnell AG and Bailey MJ (2000). Rapid method for coextraction of DNA and RNA from natural environments for analysis of ribosomal DNA - and rRNA-based microbial community composition. Appl. Environ. Microbiol. 66: 5488-5491.

Hamady M and Knight R (2009). Microbial community profiling for human microbiome projects: Tools, techniques, and challenges. Genome Res. 19: 1141-1152.

Hoshino YT and Matsumoto N (2005). Skim milk drastically improves the efficacy of DNA extraction from andisol, a volcanic ash soil. JARQ 39: 247-252.

Hou W, Lian B and Rothenberg S (2010). Two electrophoreses in different pH buffers to purify forest soil DNA contaminated with humic substances. Afr. J. Biotechnol. 9: 2401-2407.

Hurt RA, Qiu X, Wu L, Roh Y, et al. (2001). Simultaneous recovery of RNA and DNA from soils and sediments. Appl. Environ. Microbiol. 67: 4495-4503.

Khan ST, Horiba Y, Yamamoto M and Hiraishi A (2002). Members of the family Comamonadaceae as primary poly(3hydroxybutyrate-co-3-hydroxyvalerate)-degrading denitrifiers in activated sludge as revealed by a polyphasic approach. Appl. Environ. Microbiol. 68: 3206-3214.

Krsek M and Wellington EM (1999). Comparison of different methods for the isolation and purification of total community DNA from soil. J. Microbiol. Methods 39: 1-16.

Kumlanghan A, Liu J, Thavarungkul P, Kanatharana P, et al. (2007). Microbial fuel cell-based biosensor for fast analysis of biodegradable organic matter. Biosens. Bioelectron. 22: 2939-2944.

Logan BE, Hamelers B, Rozendal R, Schroder U, et al. (2006). Microbial fuel cells: methodology and technology. Environ. Sci. Technol. 40: 5181-5192.

Luna GM, Dell'anno A and Danovaro R (2006). DNA extraction procedure: a critical issue for bacterial diversity assessment in marine sediments. Environ. Microbiol. 8: 308-320.

Maciel BM, Santos AC, Dias JC, Vidal RO, et al. (2009). Simple DNA extraction protocol for a 16S rDNA study of bacterial diversity in tropical landfarm soil used for bioremediation of oil waste. Genet. Mol. Res. 8: 375-388.

Martínez-Alonso M, Escolano J, Montesinos E and Gaju N (2010). Diversity of the bacterial community in the surface soil of a pear orchard based on 16S rRNA gene analysis. Int. Microbiol. 13: 123-134.

Mohan SV, Raghavulu SV, Peri D and Sarma PN (2009). Integrated function of microbial fuel cell (MFC) as bioelectrochemical treatment system associated with bioelectricity generation under higher substrate load. Biosens. Bioelectron. 24: 2021-2027.

Muyzer G, de Waal EC and Uitterlinden AG (1993). Profiling of complex microbial populations by denaturing gradient gel electrophoresis analysis of polymerase chain reaction-amplified genes coding for 16S rRNA. Appl. Environ. Microbiol. 59: 695-700.

Ning J, Liebich J, Kastner M, Zhou J, et al. (2009). Different influences of DNA purity indices and quantity on PCR-based DGGE and functional gene microarray in soil microbial community study. Appl. Microbiol. Biotechnol. 82: 983-993.

Peng L, Chaoqun H, Lüping Z, Chunhua R, et al. (2007). Effects of DNA extraction and universal primers on 16S rRNA gene-based DGGE analysis of a bacterial community from fish farming water. Chin. J. Oceanol. Limnol. 25: 310316.

Rezaei F, Xing D, Wagner R, Regan JM, et al. (2009). Simultaneous cellulose degradation and electricity production by Enterobacter cloacae in a microbial fuel cell. Appl. Environ. Microbiol. 75: 3673-3678.

Rojas-Herrera R, Narvaez-Zapata J, Zamudio-Maya M and Mena-Martinez ME (2008). A simple silica-based method for metagenomic DNA extraction from soil and sediments. Mol. Biotechnol. 40: 13-17.

Ryu EY, Kim M and Lee SJ (2011). Characterization of microbial fuel cells enriched using Cr(VI)-containing sludge. $J$. Microbiol. Biotechnol. 21: 187-191.

Sarma PM, Duraja P, Deshpande S and Lal B (2010). Degradation of pyrene by an enteric bacterium, Leclercia adecarboxylata PS4040. Biodegradation 21: 59-69.

Schneegurt MA, Dore SY and Kulpa CF Jr (2003). Direct extraction of DNA from soils for studies in microbial ecology. Curr. Issues Mol. Biol. 5: 1-8.

Scott K and Murano C (2007). A study of a microbial fuel cell battery using manure sludge waste. J. Chem. Technol. Biotechnol. 82: 809-817.

Sohn JH, Kwon KK, Kang JH, Jung HB, et al. (2004). Novosphingobium pentaromativorans sp. nov., a high-molecularmass polycyclic aromatic hydrocarbon-degrading bacterium isolated from estuarine sediment. Int. J. Syst. Evol. Microbiol. 54: 1483-1487. 
Vanysacker L, Declerck SA, Hellemans B, De Meester L, et al. (2010). Bacterial community analysis of activated sludge: an evaluation of four commonly used DNA extraction methods. Appl. Microbiol. Biotechnol. 88: 299-307.

Venkata MS, Mohanakrishna G and Sarma PN (2010). Composite vegetable waste as renewable resource for bioelectricity generation through non-catalyzed open-air cathode microbial fuel cell. Bioresour Technol. 101: 970-976.

Wang Q, Garrity GM, Tiedje JM and Cole JR (2007). Naive Bayesian classifier for rapid assignment of rRNA sequences into the new bacterial taxonomy. Appl. Environ. Microbiol. 73: 5261-5267.

Wechter P, Williamson J, Robertson A and Kluepfel D (2003). A rapid, cost-effective procedure for the extraction of microbial DNA from soil. World J. Microbiol. Biotechnol. 19: 85-91.

Zhou J, Bruns MA and Tiedje JM (1996). DNA recovery from soils of diverse composition. Appl. Environ. Microbiol. 62: 316-322.

Zhua D, Wanga G, Qiao H and Cai J (2008). Fermentative hydrogen production by the new marine Pantoea agglomerans isolated from the mangrove sludge. Int. J. Hydrogen Energ. 33: 6116-6123. 